\title{
Shape Memory Effect and Mechanical Properties of Carbon Nanotube/Shape Memory Polymer Nanocomposites
}

Qing-Qing Ni ${ }^{* a}$, Chun-sheng Zhang ${ }^{\mathrm{b}}$, Yaqin $\mathrm{Fu}^{\mathrm{c}}$, GuangZhe Dai ${ }^{\mathrm{d}}$, and Teruo Kimura ${ }^{\mathrm{b}}$

a (1) Key Laboratory of Advance Textile Materials \& Manufacturing Technology of Ministry of Education, Zhejian Sci-Tech University

Xiasha Higher Education Zone, Hangzhou 310018, China

(2) Dept of Functional Machinery and Mechanics, Shinshu University

3-15-1 Tokida, Ueda 386-8576, Japan

${ }^{b}$ Division of Advance Fibro-Science, Kyoto Institute of Technology

Matsugasaki sakyo-ku, Kyoto 606-8585, Japan

${ }^{\mathrm{c}}$ Key Laboratory of Advance Textile Materials \& Manufacturing Technology of Ministry of Education, Zhejian Sci-Tech University

Xiasha Higher Education Zone, Hangzhou 310018, China

${ }^{\mathrm{d}}$ School of Materials Science \& Engineering, Southwest Jiaotong University Chengdu, Sichuan 610031, China

* Corresponding author

E-mail: niqq@shinshu-u.ac.jp

Fax: $+81-268-215438$

Tel: +81-268-215438 


\begin{abstract}
:
Carbon nanotubes (CNT) have remarkable mechanical properties with very high elastic modulus and electrical conductivity. Shape memory polymer (SMP) as one of smart materials is characterized with its remarkable recoverability and shape memory effect, but its mechanical properties such as strength and elastic modulus is not high enough. In this study, CNT/SMP nanocomposites were developed with the typical CNTs of the vapor growth carbon fibers (VGCFs). A fine and homogeneous dispersion of VGCF throughout the SMP matrix is obtained. The specimens with different VGCF weight fraction, such as SMP bulk, 1.7 wt $\%$, 3.3 $\mathrm{wt} \%$ and $5.0 \mathrm{wt} \%$, were prepared, and their dynamic mechanical properties and shape recovery behavior were investigated. It was found that storage elastic modulus is improved obviously with increment of VGCF weight fraction, and the CNT/SMP nanocomposites showed a good shape memory effect. It is indicated that the recovery stress of CNT/SMP nanocomposites with only $3.3 \%$ weight fraction of carbon nanotubes will reach almost twice of that in SMP bulk.
\end{abstract}

Key word: Carbon nanotube, Shape memory polymer, Nanocomposites, Shape memory effect, Shape recovery, Recovery stress 


\section{Introduction}

Carbon nanotubes (CNTs) are seamlessly rolled sheets of hexagonal array of carbon atoms with diameter ranging from a few Angstroms to several tens of nanometers. Carbon nanotubes are receiving steadily increasing attention because of their unique structural and electrical characteristics. The tensile modulus and strength of CNTs reach $270 \mathrm{GPa}$ to $1 \mathrm{TPa}$ and 11-200 GPa, respectively [1-4]. The unusual electrical and mechanical properties of carbon nanotubes have motivated a flurry of interests to exploit their applications in advanced composite materials, particularly polymer based composites, to improve the performance of a matrix or to achieve new properties [5]. Polymer composites with CNTs were expected to improve the mechanical properties of the matrix polymer. Recently, because a large quantity composition technology was established, the cost of CNT decreased and then the applications to various fields became more and active. Many researches on mechanical, thermal and electric characterizations of CNT reinforced polymers are reported, such as CNT/polystyrene [6-8], CNT/PVA [9], CNT/PVDF [10], CNT/PP [11-17], CNT/nylon [18], and CNT/epoxy [19-21] etc.

One the other hand, shape memory polymers (SMPs) have the characteristics such as large recoverability, lightweight, superior molding property and lower cost. These advantages have resulted in that the SMPs become one of functional materials with much attention from many fields [22-24]. Figure 1 shows the schematic representation of four steps of the shape memory effect in SMPs. This was based on thermo-elastic phase transformation and its reversal at the temperatures above and below $\mathrm{T}_{\mathrm{g}}$. When the SMPs were heated at fluxing temperature over $\mathrm{T}_{\mathrm{g}}$ and formed into a specified shape by compression, extrusion or injection moldings they memorized the formed shape (step 1). In this situation, it is considered that there exist two phases, stationary phase and reversible phase, which correspond to the crystal portion with bridging construction and the amorphous portion, respectively. The amorphous portion shows the rubber elasticity by heating above $\mathrm{T}_{\mathrm{g}}$, and is easy to be deformed into an arbitrary shape under an applied force (step 2). Then, the deformed shape is fixed by cooling below $\mathrm{T}_{\mathrm{g}}$ (step 3). This was 
called shape fixity in shape memory behavior. To change the deformed shape, SMPs could recover the memorized shape by heating over glass transition temperature under a free load condition (step 4), and then go through the process again as above [25-29].

For shape memory polymer (SMP) of polyurethane series, its glass transfer temperature $\left(\mathrm{T}_{\mathrm{g}}\right)$ may be set up around room temperature, and its characterizations such as shape recovery and/or shape fixation may appear to be quite different at the temperature above and below $\mathrm{T}_{\mathrm{g}}[30-35]$. Thus the polyurethane SMP will have wide applications in the field of industry as an actuation material. However, their lower mechanical properties such as strength and stiffness result in the current limited application. The low stiffness of SMP resins only produces a relatively small recovery force in a temperature change process. Thus, a few researches have studied adding reinforcement to SMP for improvement of mechanical property. C. Liang et al. [36] report that glass fiber and the Kevlar fiber reinforced SMP increased stiffness and Young's modulus, and decreased a recoverable strain. Ken Gall et al. [37] presented that SiC reinforced SMP nanocomposites increased elastic modulus by approximately a factor of 3 with the addition of $40 \mathrm{wt} \% \mathrm{SiC}$, and permanent bend stain were discovered. The present authors group [38-41] demonstrated that the relationship between fiber weight fraction and recoverability for chopped strand glass fiber reinforced SMP composites by injection molding. It is found that the composite stiffness and recoverable strain levels depend strongly on the fiber weight fraction. The material with $50 \mathrm{wt} \%$ fraction of glass fiber will increase failure stress $140 \%$ and decrease recovery rate $62 \%$ compared with the bulk one.

The study of SMP nanocomposites with carbon nanotubes (CNTs) has not been reported. Using carbon nanotubes may obtain higher performance than usual reinforcement due to the large surface area of carbon nanotubes. In this paper, CNT/SMP nanocomposites were innovated with different CNT weight fractions. The fundamental mechanical properties and shape recovery behavior of CNT/SMP nanocomposite were examined. The tensile properties were evaluated at the temperature above and below $\mathrm{T}_{\mathrm{g}}$. The thermo-mechanical cycle tests were carried out for 
evaluating the influence of CNT weight fraction on shape memory effects. And the recovery stress test was also conducted in order to investigate the influence of CNT weight fraction on recovery stress.

\section{Experimental}

\subsection{Material}

Vapor grown carbon fibers (VGCFs) (Showa Denko K.K.), one of typical carbon nanotubes, is used. The diameter of VGCF is about $150 \mathrm{~nm}$ and length is $10 \sim 20 \mu \mathrm{m}$. The polyesterpolyol series of polyurethane SMP (Diary, MS4510) was used and its glass transition temperature $\mathrm{T}_{\mathrm{g}}$ was about $45^{\circ} \mathrm{C}$. The raw material was liquid. The weight ratio of polymer to solvent is set to be $3: 7$.

\subsection{Fabrication of specimens}

VGCFs were put into the solvent little by little and dispersed for $3 \mathrm{~h}$ by ultrasonic vibration at $45^{\circ} \mathrm{C}$. The diluted SMP solution is gradually poured into the mixed-solution of VGCF and solvent, and then whole mixture was agitated for $3 \mathrm{~h}$. The mixture was cast into the container and dried at $70^{\circ} \mathrm{C}$, and then $\mathrm{CNT} / \mathrm{SMP}$ nanocomposites were prepared. In order to vaporize water completely, the CNT/SMP nanocomposites were dried at $110^{\circ} \mathrm{C}$. The weight fraction of VGCF was $1.7 \mathrm{wt} \%, 3.3 \mathrm{wt} \%$ and $5.0 \mathrm{wt} \%$, respectively. The pure SMP films were also prepared in a similar manner. CNT/SMP nanocomposites were examined in a scanning electron microscope (SEM) in order to observe the distribution of VGCFs in nanocomposites. The SEM image of 5.0wt\% VGCFs was shown in Fig.2. It could be found that the VGCFs exhibited relatively good dispersion in SMP and were randomly distributed. VGCFs were observed to be 100 200 nanometers in diameter and several microns in length. However, when the VGCF weight fraction exceeds $6.7 \mathrm{wt} \%$, the material cannot be fabricated for testing due to too much VGCF's, resulting in frangible specimen. The weight fraction together with the size of carbon nanotube will be very sensitive parameters to their distribution in SMP nonocomposites due to the large surface of CNTs.

The dumbbell specimen was fabricated in accordance with JIS K6251 by a standard dumbbell 
cutter (Type SDK- 300). Figure 3 shows the geometric shape of the specimen.

\subsection{Experimental procedure}

The experimental equipment used was an Instoron Universal Testing Instrument (Type 4466) with a temperature-controlled chamber. The heating and/or cooling the specimen is controlled by an air-conditioner. The temperature was measured by the thermocouple that was installed near the specimen.

\subsubsection{Static tensile test}

The static tensile test was conducted at a constant tensile speed with different temperature conditons. The tensile speed was $10 \mathrm{~mm} / \mathrm{min}$ and the temperatures of chamber were set at $25^{\circ} \mathrm{C}$ $\left(<\mathrm{T}_{\mathrm{g}}\right), 45^{\circ} \mathrm{C}$ and $65^{\circ} \mathrm{C}\left(>\mathrm{T}_{\mathrm{g}}\right)$, respectively.

The strain was calculated by the ratio of the elongation obtained by the crosshead displacement to the gage length $(20 \mathrm{~mm})$ with a maximum of $300 \%$.

\subsubsection{Thermo-mechanical cycle test}

The shape recovery of SMP bulk occurs when the polymer subjected to thermo-mechanical cycle [32]. In order to investigate the shape recovery property of the developed nanocomposite, the thermo-mechanical cycle test was conducted. Figure 4 shows the schema of the thermo-mechanical cycle test. The specimen was pulled up to maximum strain $\varepsilon_{\mathrm{m}}$ at a constant tensile speed at the high temperature $\mathrm{T}_{\mathrm{h}}$ above $\mathrm{T}_{\mathrm{g}}$ (at the rubbery state) (Process 1). Maintaining the strain at $\varepsilon_{\mathrm{m}}$, the specimen was cooled to the low temperature $\mathrm{T}_{1}$ below $\mathrm{T}_{\mathrm{g}}$ (at the glassy state) and kept for 20 minutes (Process 2). The specimen was unloaded at the temperature $\mathrm{T}_{1}$ (Process 3 ), where small unloading strain $\varepsilon_{\mathrm{u}}$ occurred. Then the specimen was heated from $T_{1}$ to $T_{h}$ under no-load and kept for 5 minutes (Process 4), where the strain of the specimen was recovered. This is one completed thermo-mechanical cycle. When this one cycle is finished a residual strain, $\varepsilon_{\mathrm{u}}$, is remained. The test was repeated to 5 cycles.

The thermo-mechanical cycle test conditions were set as $\mathrm{T}_{\mathrm{h}}=65^{\circ} \mathrm{C}, \mathrm{T}_{\mathrm{l}}=25^{\circ} \mathrm{C}$, the maximum strain $\varepsilon_{\mathrm{m}}=100 \%$. And loading and unloading speed was $10 \mathrm{~mm} / \mathrm{min}$, and the heating or cooling 
speed was $8^{\circ} \mathrm{C} / \mathrm{min}$.

\subsubsection{Recovery stress test}

The schema of stress-strain- temperature curves in a recovery stress test is shown in Fig.5. The loading or unloading conditions in the recovery stress test was almost the same as in the thermo-mechanical cycle test. However, in the process 4, the specimen was kept for 10 minutes at low temperature $T_{1}$ under no-load and then the test distance of the specimen was adjusted to have a constant strain. After that the specimen was heated from $T_{1}$ to $T_{h}$ and kept for 5 minutes at $\mathrm{T}_{\mathrm{h}}$ under a constraint strain condition and the recovery stress was measured (process 5). In process 6 , it was unloaded at $\mathrm{T}_{\mathrm{h}}$.

\section{Results and discussions}

\subsection{Static tensile property}

Typical stress-strain curve for three kinds of nanocomposite with different VGCFs weight fraction and SMP bulk were shown in Fig. 6 at three testing temperature $25^{\circ} \mathrm{C}, 45^{\circ} \mathrm{C}$, and $65^{\circ} \mathrm{C}$. The young's modulus, yield stress and the tensile stress at each temperature became large when the VGCF weight fraction increased. Thus it is clear that mechanical properties of shape memory polymer (SMP) are reinforced by VGCF carbon nanotubes. The developed nanocomposites were not broken within the strain range of $300 \%$ (the maximum limit of the instrument due to the chamber). This shows they have excellent ductility similar to SMP bulk.

When the testing temperature was $25^{\circ} \mathrm{C}\left(<\mathrm{T}_{\mathrm{g}}\right)$, the yield point was observed clearly in all specimens. The yield region became long when VGCFs weight fraction increased. After the yield point, the inclination of the stress-strain curve increased with the increase of strain. That is to say, a strain-hardening phenomenon occurred.

When the testing temperature was $45^{\circ} \mathrm{C}$ and $65^{\circ} \mathrm{C}\left(>\mathrm{T}_{\mathrm{g}}\right)$, the yield phenomenon also appeared slowly even if at the lower stress level. When the strain exceeded $30 \%$, the stress increased gradually with the increment of the strain, and the increment rate in this region became large 
when the temperature became lower. The stress yielding and strain hardening are generated by turns for all specimens in the plastic deformation region.

The relationships between the VGCFs weight fraction and Young's modulus at each testing temperature is shown in Fig.7. The relationships between the VGCF weight fraction and yield stress is shown in Fig.8. For the 5.0wt\% VGCF nanocomposite at each temperature, compared with SMP bulk, the high young's modulus were observed with the increment of $125 \%, 216 \%$ and $186 \%$ at $25^{\circ} \mathrm{C}, 45^{\circ} \mathrm{C}$, and $65^{\circ} \mathrm{C}$, while the yield stress had the increment of $87 \%, 132 \%$ and $138 \%$, respectively. Both Young's modulus and tensile strength at temperature below $\mathrm{T}_{\mathrm{g}}$ were much larger than that above $\mathrm{T}_{\mathrm{g}}$ where the deformation resistance was small. The reason of these deformation characteristics appeared is considered as follows. The shape memory polymer used in this study is a kind of segmental polyurethane which is composed of the flexible soft segment and the rigid hard segment with a specified ratio. The micro-Brownian motion of the soft segment was frozen at low temperature. For this reason, at the temperature below $\mathrm{T}_{\mathrm{g}}$, deformation resistance is large. However, when temperature rises, especially above $\mathrm{T}_{\mathrm{g}}$, since soft segment exercises easily, and then deformation will become easy. This will result in the big difference for the mechanical properties below and above $T_{g}[33]$.

\subsection{Shape fixity and shape recovery property}

The stress-strain curves obtained in the thermo-mechanical cycle test of the maximum strain $\varepsilon_{m}=100 \%$ for CNT/SMP nanocomposites and SMP bulk were shown in Fig.9. Observing the same cycle number, when the VGCF weight fraction in CNT/SMP nanocomposites became high, the stress at the maximum strain became large, and the residual strain increased. The stress corresponding to any strain value during cycle loading also increased with the VGCF weight fraction, but the tendency of stress-strain curve on cycle number in CNT/SMP nanocomposites with 1.7, 3.3 and 5.0wt $\%$ of VGCFs weight fraction, respectively, is similar to that in SMP bulk. When cycle number increased the variation of stress-strain loop was large at an early stage, and it became small pronouncedly after cycle number $\mathrm{N}=2$. The shape of stress-strain loop was 
almost the same after two cycles $(\mathrm{N}>2)$ although it moves to the higher strain side. The residual strain $\varepsilon_{p}(N)$ increased slowly accompanying with the reduction of recovery strain. This means that the addition of carbon nanotubes up to $5.0 \mathrm{wt} \%$ weight fraction will not only make rise of the mechanical property but also almost keep the shape fixture property similar to the SMP bulk.

When the developed nanocomposites were cooled to the low temperature $T_{1}$ and kept for 20 minutes under the maximum strain $\varepsilon_{\mathrm{m}}$ (Process 2) stress in CNT/SMP nanocomposites decreased firstly due to stress relaxation and then increased due to heat contraction at $T_{1}$ during one cycle. The relationship between stress and time was shown in Fig.10 for the first typical cycle. The curves shifted to the high stress level with the increase of VGCF weigh fractions. The stress relaxation was large but thermal contraction stress was small in the cooling process of low temperature $T_{1}$. Relaxation time became short with the increment VGCF weight fraction. However, the thermal stress became large due to heat contraction and relatively large Young's modulus at $T_{1}$, so that the stress in Fig.10 increased obviously accompanying with the thermal contraction. The stress increment became blunt and tended to constant after about 25 minutes.

The shape recovery property of CNT/SMP nanocomposites was examined from the result of thermo-mechanical cycle tests as above. The shape memory effect relative to both strain fixity and strain recovery were evaluated by using both strain fixity ratio and strain recovery ratio at cycle number $N$ as defined by Eq.(1). The strain recovery ratio considering the residual strain per each cycle was used.

$$
\begin{aligned}
& R_{f}(N)=\frac{\varepsilon_{u}(N)-\varepsilon_{p}(N-1)}{\varepsilon_{m}-\varepsilon_{p}(N-1)} \\
& R_{r}(N)=\frac{\varepsilon_{u}(N)-\varepsilon_{p}(N)}{\varepsilon_{u}(N)-\varepsilon_{p}(N-1)}
\end{aligned}
$$

Where $R_{f}(N)$ and $R_{r}(N)$ is the strain fixity ratio and the strain recovery ratio in the cycle number $N, \varepsilon_{u}(N)$ is the unloading strain in the process 3 at $T_{l}$ in the cycle number $N, \varepsilon_{p}(N)$ and $\varepsilon_{p}(N-1)$ were residual strain in the cycle number $N$ and $N-1$. 
From Fig.9, the unloading strains almost toke the fixed value near the maximum strain. The strain fixity ratio $R_{f}(N)$ for each specimen was about $95 \%$. It is clear that the developed nanocomposites have good shape fixed property.

The relationship between the strain recovery ratio and the cycle number was shown in Fig.11.

In the first cycle, the strain recovery ratio $R_{r}(1)$ in CNT/SMP nanocomposites was less than $80 \%$ and decreased with the VGCF weight fraction due to the addition of carbon nanotunbes. This is due to inclusion interaction of VGCFs in shape memory polymer and it results in the reduction of shape memory effect. However, after the second cycle the CNT/SMP nanocomposites had the strain recovery ratio increasing from less than $80 \%$ to more than $90 \%$ and tended to be constant $95 \%$ after more cycle numbers. This phenomenon may be called as a training effect. The training effect for the SMP bulk had been reported by Tobushi et al. [32] and confirmed by Ohki et al. [40]. Hence, for the developed nanocomposites with reinforcement carbon nanotubes, it was found that stable strain recovery ability after several cycles of training could be obtained.

\subsection{Recovery stress property}

The stress-strain curves obtained in the recovery stress test for CNT/SMP nanocomposites and SMP bulk were shown in Fig.12. The load curve and unload curve in the developed nanocomposites were silimar to those in thermo-mechanical cycle tests. The specimens were kept for 10 minutes under stress free at low temperature $T_{1}$ after unloading. It was observed in situ that the strain was recovered slowly during the keeping time. This recovered strain decreased with the increment of VGCF weight fraction. The recovered strain for $3.3 \mathrm{wt} \%$ and $5.0 \mathrm{wt} \%$ VGCF was almost the same. The developed nanocomposites kept better shape fixed property than SMP at low temperature. In order to measure the recovery stress for the application of actuator, such as temperature sensors etc., the strain was restrained by fix the specimen distance (see the heating recovery process (Process 5) in Fig.5), and then recovery stress was measured.

The relationship between the recovery stress and the VGCF fraction was shown in Fig.13. It is 
clear that the recovery stress of CNT/SMP nanocomposites is larger than SMP bulk. Especially, for the nanocomposites of $3.3 \mathrm{wt} \%$ VGCF weight fraction, the recovery stress increased about 2 times as large as that in SMP bulk. The reason for this result could be considered as that when a specimen was loaded under both constant strain and high temperature and then cooled to low temperature and unloaded, the carbon nanotubes may store elastic strain energy. When reheating the specimen, this stored elastic strain energy will release and CNT/SMP nanocomposites obtain larger recovery stress [37]. However, when carbon nanotubes exceed a specified amount, since the interaction carry out between carbon nanotubes and shape memory polymer and also between carbon nanotubes, the internal stored elastic strain energy may waste so the recovery stress decreases.

\section{Conclusions}

The nanocomposites composed of carbon nanotubes (CNT) and shape memory polymer (SMP) were innovated, and their mechanical properties and shape recovery behavior were investigated. The results obtained are remarked as follows.

1. Young's modulus and yield stress increased with the increment of VGCF weight fraction at any temperature. It is confirmed that there existed a strong temperature dependency of young's modulus in the CNT/SMP nanocomposites.

2. The developed nanocomposites have excellent shape recoverability. They can keep high strain recovery ability more than $90 \%$ after several cycles of training. This will lead that the developed materials can be utilized for the cycle use with any shape in daily life.

3. The recovery stress of CNT/SMP nanocomposites is much larger than SMP bulk. For the nanocomposite with $3.3 \mathrm{wt} \% \mathrm{VGCF}$ weight fraction, the recovery stress is about twice as large as that in SMP bulk. This characterization may be expected to the application of temperature sensor materials for CNT/SMP nanocomposites. 


\section{References}

1) Iijima S. Helical microtubules of graphitic carbon. Nature 1991; 354: 56-8.

2) Subramoney S. Novel nanocarbons-structure, properties, and potential applications. Adv Mater 1998; 15: 1157-71.

3) Wong EW, Sheehan PE, Lieber CM. Nanobeam mechanics: Elasticity, Strength, and Toughness of nanorods and nanotubes. Science 1997; 277: 1971-5.

4) Rao CNR, Satishkumar BC, Govindaraj A, Nath M. Nanotubes. Chemphyschem 2001; 2: 78 -105 .

5) Baughman RH, Zakhidov AA, Heer WAD. Carbon nanotubes-the route toward applications. Science 2002; 297: 787-92.

6) Xu Y, Higgins B, Brittain WJ. Bottom-up synthesis of PS-CNF nanocomposites. Polymer 2005; 46: 799-810

7) Lou X, Detrembleur C, Sciannamea V, Pagnoulle C, Jerome R. Grafting of alkoxyamine end-capped (co)polymers onto multi-walled carbon nanotubes. Polymer 2004; 45: 6097-102.

8) Wong M, Paramsothy M, Xud XJ, Ren Y, Li S, Liao K. Physical interactions at carbon nanotube-polymer interface. Polymer 2003; 44: 7757-64.

9) Shaffer MSP, Windle A H. Fabrication and characterization of carbon nanotube/poly(vinyl alcohol) composites. Adv Mater 1999; 11: 937-41.

10) Seoul C, Kim Y-T, Baek C-K. Electrospinning of poly(vinylidene fluoride)/ dimethylformamide solutions with carbon nanotubes. J Polym Sci Part B: Polym Phys 2003; 41: 1572-7.

11) Seo M-K, Park S-J. A kinetic study on the thermal degradation of multi-walled carbon nanotubes-reinforced poly(propylene) composites. Macromol Mater Eng 2004; 289: 368-74

12) Bhattacharyya AR, Sreekumar T V, Liu T, Kumar S, Ericson LM, Hauge RH, Smalley RE. Crystallization and orientation studies in polypropylene/single wall carbon nanotube 
composite. Polymer 2003; 44: 2373-7.

13) Chang TE, Jensen LR, Kisliuk A, Pipes RB, Pyrz R, Sokolov AP. Microscopic mechanism of reinforcement in single-wall carbon nanotube/polypropylene nanocomposite. Polymer 2005; 46: 439-44.

14) Kashiwagi T, Grulke E, Hilding J, Groth K, Harris R, Butler K, Shields J, Kharchenko S, Douglas J. Thermal and flammability properties of polypropylene/carbon nanotube nanocomposites. Polymer 2004; 45: 4227-39.

15) Kumar S, Doshi H, Srinivasarao M, Park JO, Schiraldi DA. Fiber from polypropylene/nano carbon fiber composites. Polymer 2002; 43: 1701-3

16) Assouline E, Lustiger A, Barber AH, Cooper CA, Klein E, Wachtel E, Wagner HD. Nucleation ability of multiwall carbon nanotubes in polypropylene composite. J Polym Sci Part B: Polym Phys 2003; 41: 520-7.

17) Kashiwagi T, Grulke E, Hilding J, Harris R, Awad W, Douglas J. Thermal degradation and flammability properties of poly(propylene)/carbon nanotube composites. Macromol Rapid Commun 2002; 23: 761-5.

18) Liu T, Phang IY, Shen L, Chow SY, Zhang W-D. Morphology and mechanical Properties of multiwalled carbonNanotubes reinforced nylon-6 composites. Macromolecules 2004; 37: 7214-22.

19) Kao CC, Young RJ. A Raman spectroscopic investigation of heating effects and the deformation behaviour of epoxy/SWNT composites. Compos Sci and Technol 2004; 64: 2291-5.

20) Gojny FH, Schulte K. Functionalisation effect on the thermo-mechanical behaviour of multi-wall carbon nanotube/epoxy-composites. Compos Sci and Technol 2004; 64: 2303-8.

21) Sandler JKW, Kirk JE, Kinloch IA, Shaffer1 MSP, Windle AH. Ultra-low electrical percolation threshold in carbon-nanotube-epoxy composites. Polymer 2003; 44: 5893-9.

22) Toray research center investigation research planning department. New applications of shape 
memory polymers. Toray research center; 1995. pp. 11-14.

23) Irie M. Development of shape memory polymers. CMC; 2000. pp 3-11.

24) Kenichi Shimizu, Masahiro Irie and zinan Yuiitu. Memory and Material, Admission of shape memory material. Kyouritu publication; 1986. pp. 121.

25) Lin JR, Chen LW. Study on shape-memory behavior of polyether-based polyurethanes. I. Influence of the hard-segment fraction. J Appl Polym Sci 1998; 69: 1563-74.

26) Lin JR, Chen LW. Study on shape-memory behavior of polyether-based polyurethanes. II. Influence of the soft-segment molecular weight. J Appl Polym Sci 1998; 69: 1575-86.

27) Otsuka K, Wayman C. Shape Memory Materials. Cambridge University Press; 1998 pp. 203-19.

28) Lendlein A, Kelch S. Shape-Memory Polymers. Angew Chem Int Ed, 2002, 41: 2034-57.

29) Lendlein A, Schmidt AM, Langer R. AB-polymer networks based on oligo( $\varepsilon$-caprolactone) segments showing shape-memory properties, PNAS, 2001, 98: 842-7.

30) Tobushi H, Hayahi S. Properties and application of shape memory polymer polyurethane series. Res Mach 1994; 46(6): 646-52.

31) Tobushi H, Hayahi S. Development and Application of Shape Memory Polymer. Res Mach 1994; 45(11): 1136-41.

32) Tobushi H, Hayahi S, Ikai A, Hara H, Miwa N. Shape fixity and shape recoverability in a film of shape memory polymer of the polyurethane series. Trans Jpn Soc Mech Eng A 1996; 62: 1291-8.

33) Tobushi H, Hayahi S, Ikai A, Hara H. Basic deformation properties of a polyurethane-series shape memory polymer film. Trans Jpn Soc Mech Eng A 1996; 62: 576-82.

34) Tobushi H, Hayahi S, Lin P-h. Deformation properties of shape memory polymers of polyurethane series. Trans Jpn Soc of Mech Eng A 1994; 60: 1676-81.

35) Tobushi H, Okumura K, Hayahi S, Ito N. Thermomechanical constitutive model of shape memory polymer. Mech Mater, 2001, 33: 545-54. 
36) Liang C, Rogers CA, Malafeew E. Investigation of shape memory polymers and their hybrid composites. J Intell Mater Sys Struct 1997; 8: 380-6.

37) Gall K, Dunn ML, Liu Y, Finch D, Lake M, Munshi NA. Shape memory polymer nanocomposites. Acta mater 2002; 50:5115-26.

38) Ohki T, Ohsako N, Ni Q-Q, Iwamoto M. Mechanical properties of smart composites based on shape memory polymer. Materials Science Research International, Special Technical Publication-2 2001; 115-20.

39) Ni Q-Q, Ohki T, Ohsako N, Iwamoto M. Development and mechanical properties of shape memory polymer. Proceeding of the 9th Japan Society of Mechanical Engineer M\&P2001, 15-16.

40) Ohki T, Ni Q-Q, Ohsako N, Iwamoto M. Mechanical and shape memory behavior of composites with shape memory polymer. Composites Part A 2004; 35: 1065-73.

41) Ni Q-Q, Ohsako N, Ohki T, Wang W, Iwamoto M. Development of smart composites based on shape memory polymer. International Symposium on Smart Structure \& Microsystems (IS3M) 2000; 1-6(C2-1) 
Figure 1. Schematic representation of the shape-memory effect with four steps: (1) memorized shape after molding and cooling; (2) free deformation due to the rubber elasticity of the amorphous portion by heating over $\mathrm{T}_{\mathrm{g}}$ under an applied force; (3) shape fixity by cooling below $\mathrm{T}_{\mathrm{g}}$; and (4) shape recovery by heating over $\mathrm{T}_{\mathrm{g}}$ under free load condition.

Figure 2. Scanning electron micrograph of 5.0wt $\%$ VGCF/SMP nanocomposite.

Figure 3. Geometric shape of specimen.

Figure 4. Schematic representation of the thermo-mechanical cycle: (1) stretching to $\epsilon_{\mathrm{m}}$ at $\mathrm{T}_{\mathrm{h}}$; (2) cooling to $T_{1}$ while $\epsilon_{\mathrm{m}}$ is kept constant; (3) keeping 20 minutes at $T_{1}$, then the load was taken off; (4heating up to $\mathrm{T}_{\mathrm{h}}$ under no-load; then start of the second cycle.

Figure 5. Three-dimensional stress-strain-temperature schematic representation of the recovery-stress cycle test with loading and unloading paths.

Figure 6. Stress-strain curves in static tensile tests for four materials-SMP bulk, $1.7 \mathrm{wt} \%$, $3.3 \mathrm{wt} \%$ and $5.0 \mathrm{wt} \%$ at testing temperatures: (a) $25^{\circ} \mathrm{C}$, (b) $45^{\circ} \mathrm{C}$, and (c) $65^{\circ} \mathrm{C}$, respectively.

Figure 7. Relationships between Young's modulus and VGCFs weight fraction for four materials - SMP bulk, $1.7 \mathrm{wt} \%, 3.3 \mathrm{wt} \%$ and $5.0 \mathrm{wt} \%$ at testing temperatures: $25^{\circ} \mathrm{C}, 45^{\circ} \mathrm{C}$, and $65^{\circ} \mathrm{C}$.

Figure 8. Relationships between yield stress and VGCFs weight fraction for four materials-SMP bulk, $1.7 \mathrm{wt} \%, 3.3 \mathrm{wt} \%$ and $5.0 \mathrm{wt} \%$ at testing temperatures: $25^{\circ} \mathrm{C}, 45^{\circ} \mathrm{C}$, and $65^{\circ} \mathrm{C}$.

Figure 9. Stress-strain curves in the thermo-mechanical cycle tests at $\varepsilon_{m}=100 \%$ for four materials-(a) SMP bulk, (b) $1.7 \mathrm{wt} \%$, (c) $3.3 \mathrm{wt} \%$ and (d) $5.0 \mathrm{wt} \%$, respectively. 
Figure 10. Relationship between stress and time at the process 2 for four materials-SMP bulk, $1.7 \mathrm{wt} \%, 3.3 \mathrm{wt} \%$ and $5.0 \mathrm{wt} \%$.

Figure 11. Relationship between strain recovery ratio and cycle number for four materials-SMP bulk, $1.7 \mathrm{wt} \%, 3.3 \mathrm{wt} \%$ and $5.0 \mathrm{wt} \%$.

Figure 12. Relationship between stress and strain in the recovery stress cycle test for four materials-(a) SMP bulk, (b) $1.7 \mathrm{wt} \%$, (c) $3.3 \mathrm{wt} \%$ and (d) $5.0 \mathrm{wt} \%$, respectively.

Figure 13. Relationships between recovery stress and VGCF weight fraction for CNT/SMP nanocomposites 


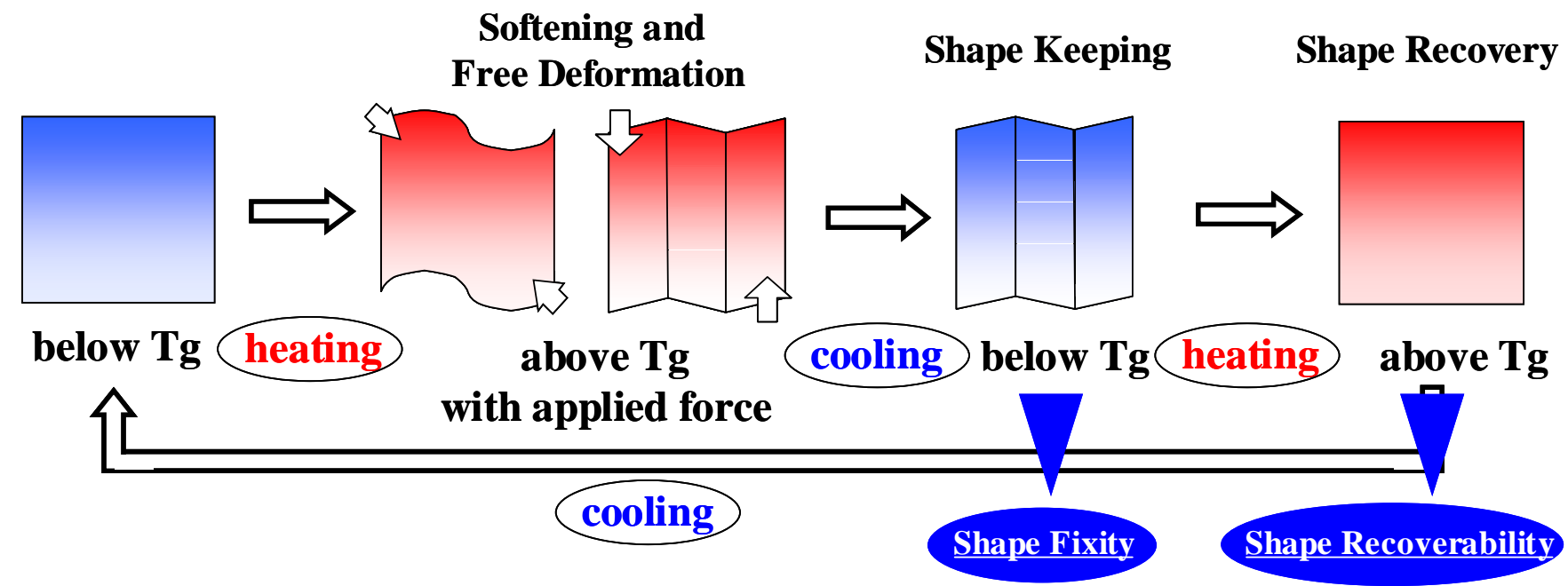

Figure 1. Schematic representation of the shape-memory effect with four steps: (1) memorized shape after molding and cooling; (2) free deformation due to the rubber elasticity of the amorphous portion by heating over $T_{g}$ under an applied force; (3) shape fixity by cooling below $T_{g}$; and (4) shape recovery by heating over $\mathrm{T}_{\mathrm{g}}$ under free load condition.

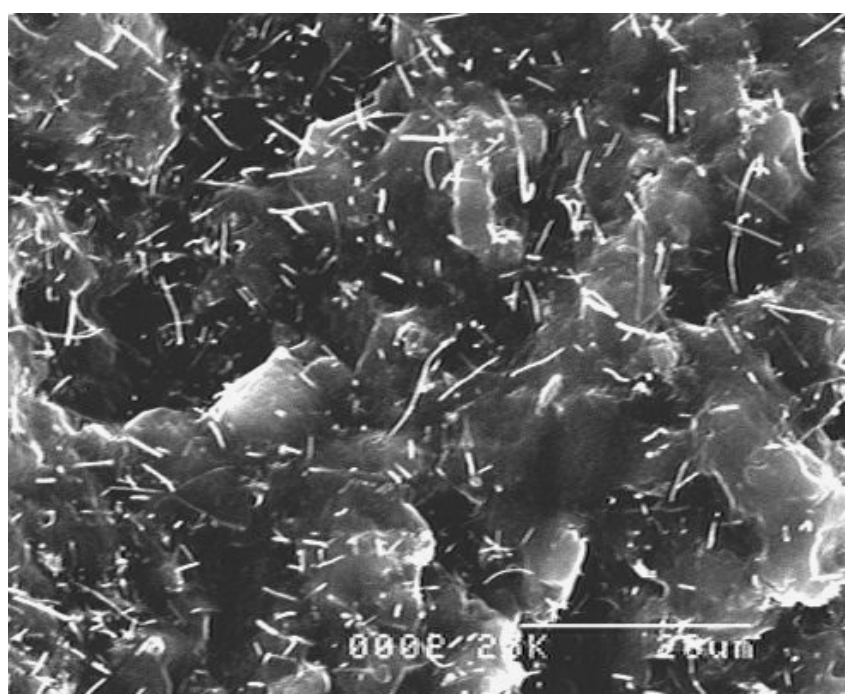

Figure 2. Scanning electron micrograph of 5.0wt\% VGCF/SMP nanocomposites. 


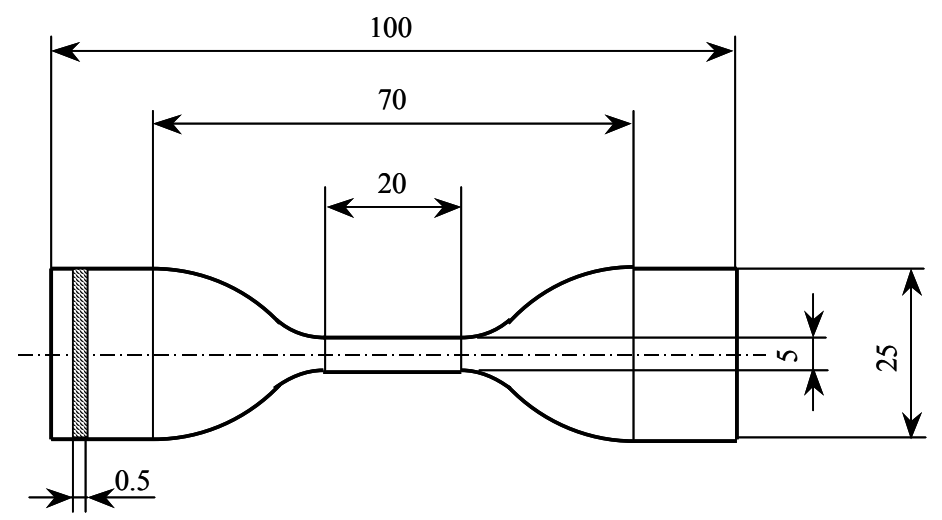

Figure 3. Geometric shape of specimen.
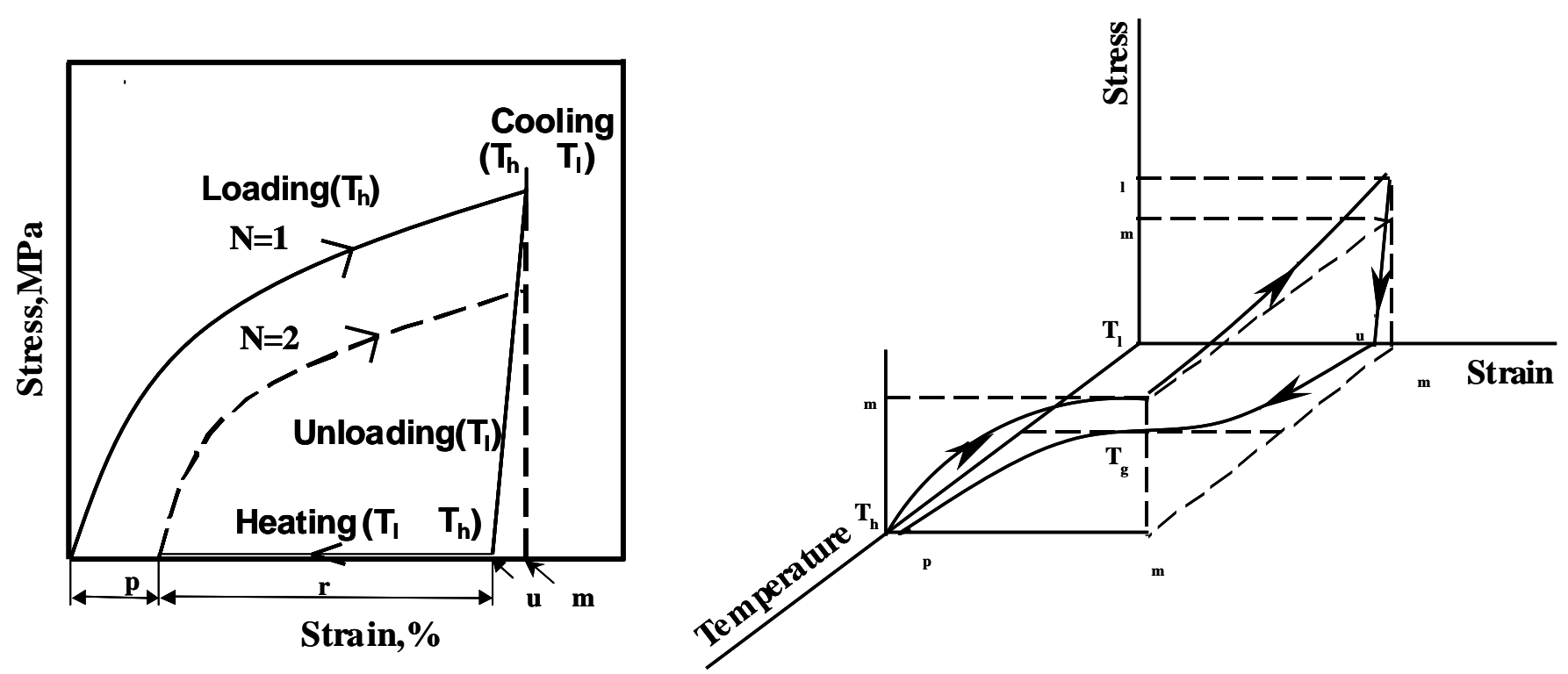

Figure 4. Schematic representation of the thermo-mechanical cycle: (1) stretching to $\epsilon_{\mathrm{m}}$ at $\mathrm{T}_{\mathrm{h}}$; (2) cooling to $\mathrm{T}_{1}$ while $\epsilon_{\mathrm{m}}$ is kept constant; (3) keeping 20 minutes at $\mathrm{T}_{1}$, then the load was taken off; (4) heating up to $\mathrm{T}_{\mathrm{h}}$ under no-load; then start of the second cycle. 


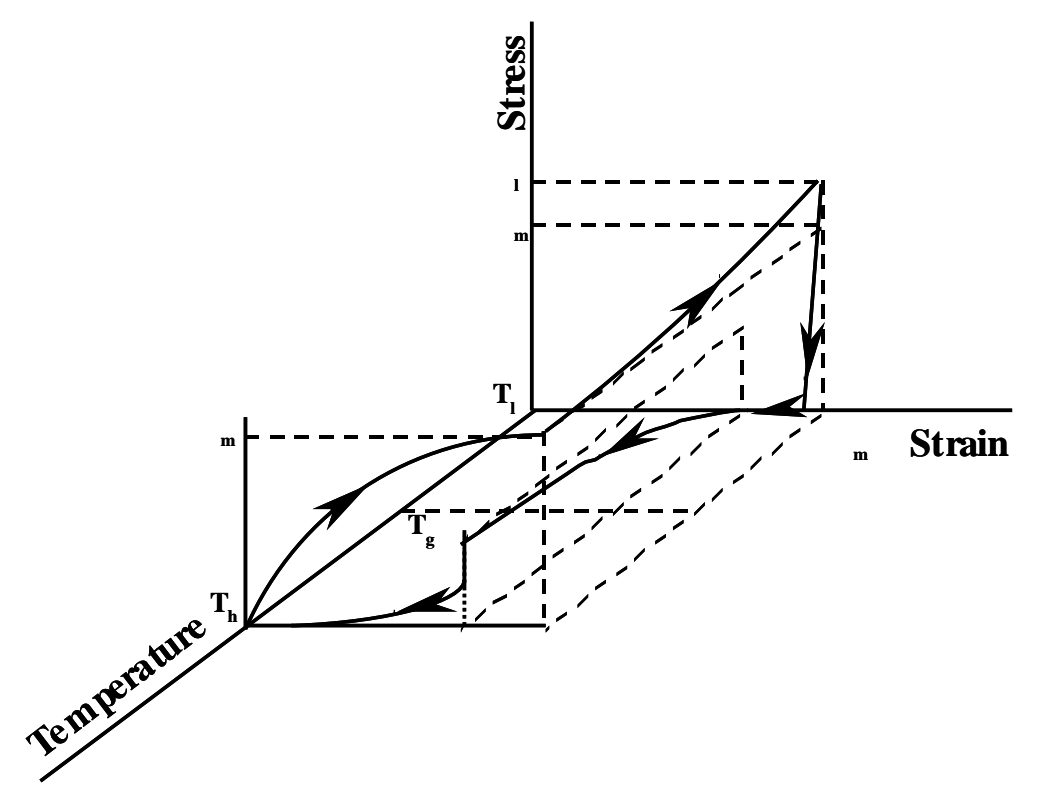

Figure 5. Three-dimensional stress-strain-temperature schematic representation of the recovery-stress cycle test with loading and unloading paths 


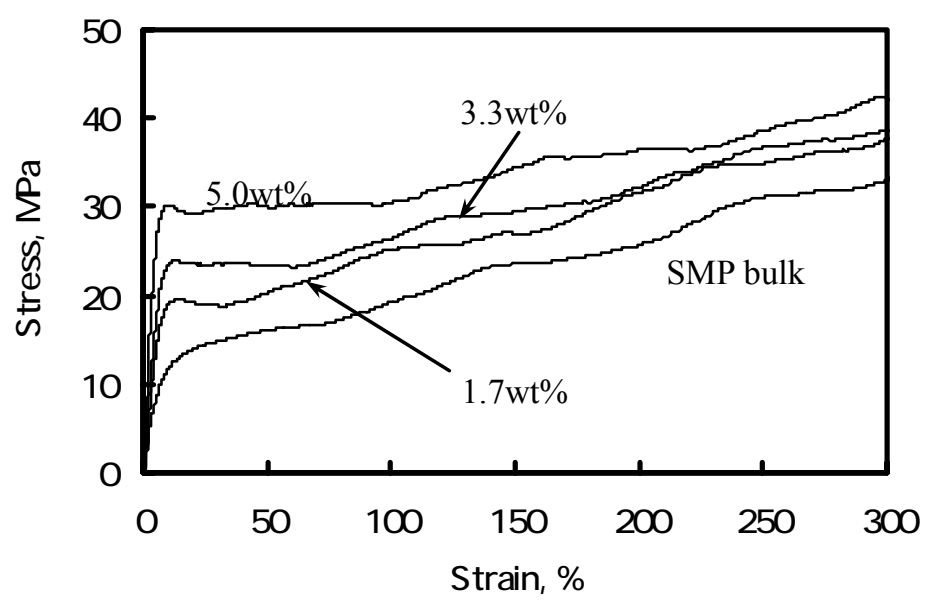

(a) $25^{\circ} \mathrm{C}$

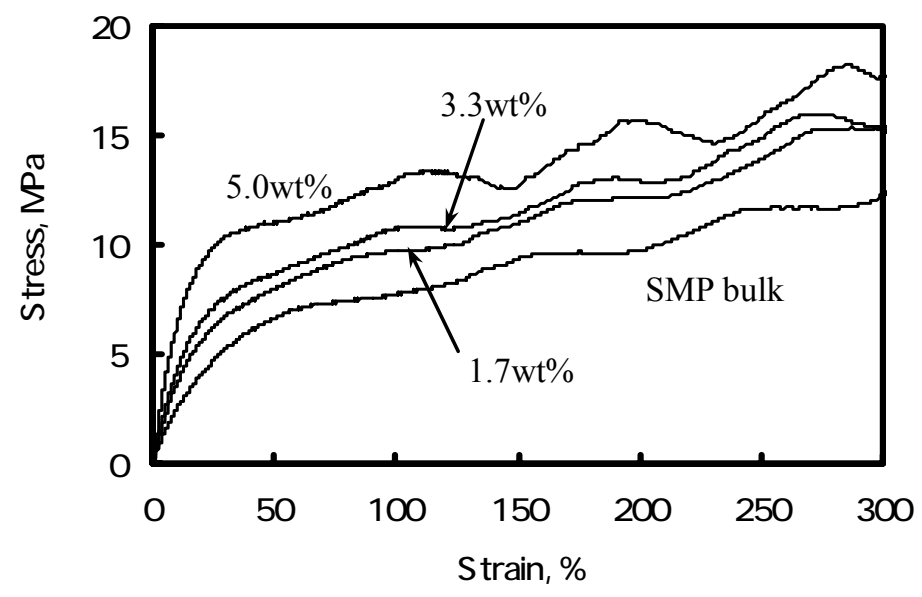

(b) $45^{\circ} \mathrm{C}$

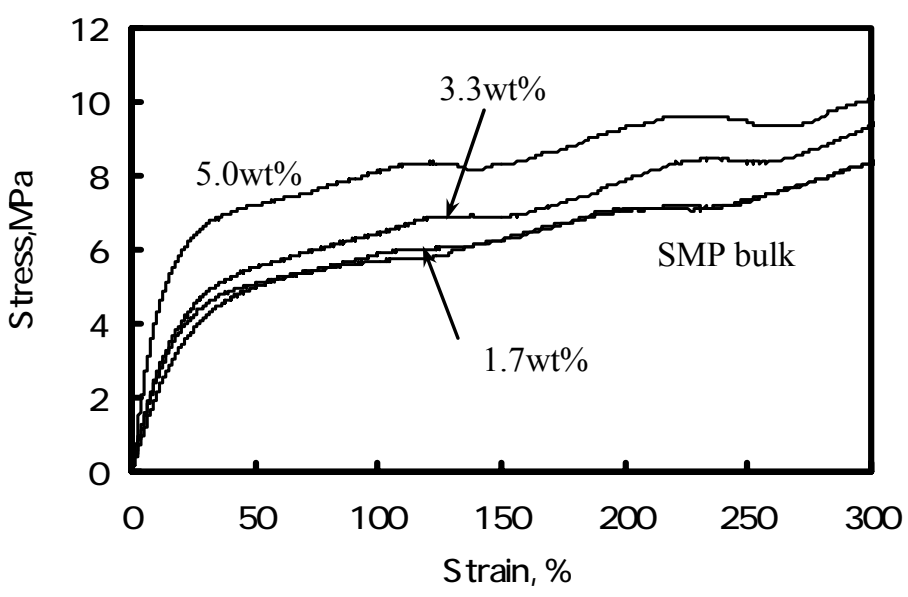

(c) $65^{\circ} \mathrm{C}$

Figure 6. Stress-strain curves in static tensile tests for four materials-SMP bulk, $1.7 \mathrm{wt} \%$, $3.3 \mathrm{wt} \%$ and $5.0 \mathrm{wt} \%$ at testing temperatures: (a) $25^{\circ} \mathrm{C}$, (b) $45^{\circ} \mathrm{C}$, and (c) $65^{\circ} \mathrm{C}$, respectively. 


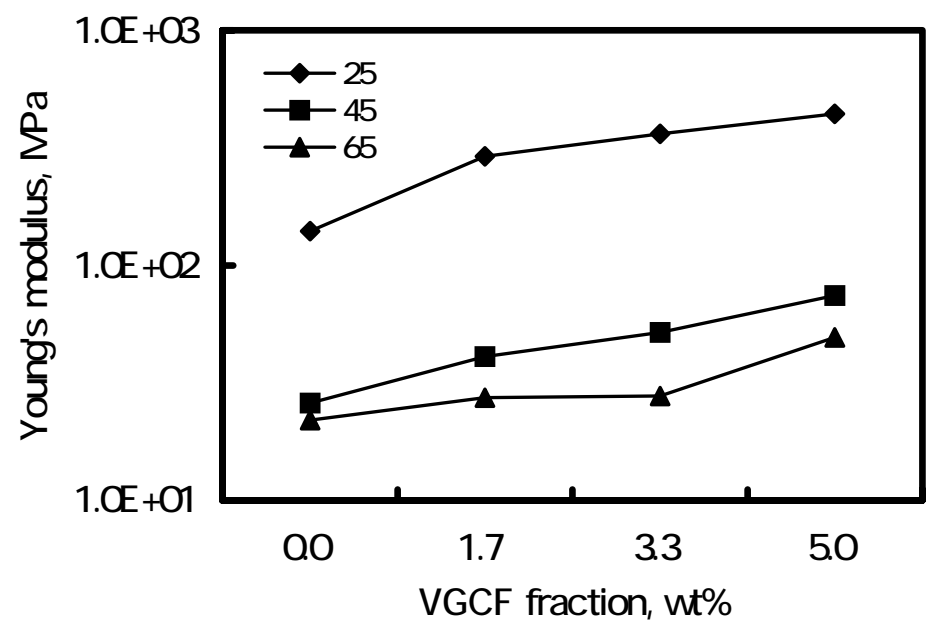

Figure 7. Relationships between Young's modulus and VGCFs weight fraction for four materials -SMP bulk, $1.7 \mathrm{wt} \%, 3.3 \mathrm{wt} \%$ and $5.0 \mathrm{wt} \%$ at testing temperatures: $25^{\circ} \mathrm{C}, 45^{\circ} \mathrm{C}$, and $65^{\circ} \mathrm{C}$.

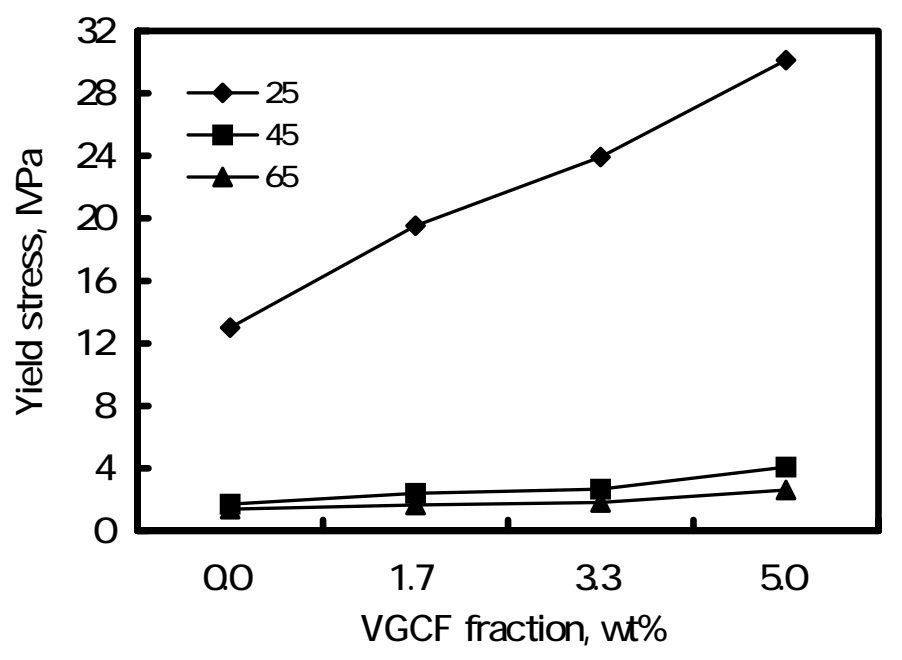

Figure 8. Relationships between yield stress and VGCFs weight fraction for four materialsSMP bulk, $1.7 \mathrm{wt} \%, 3.3 \mathrm{wt} \%$ and $5.0 \mathrm{wt} \%$ at testing temperatures: $25^{\circ} \mathrm{C}, 45^{\circ} \mathrm{C}$, and $65^{\circ} \mathrm{C}$. 


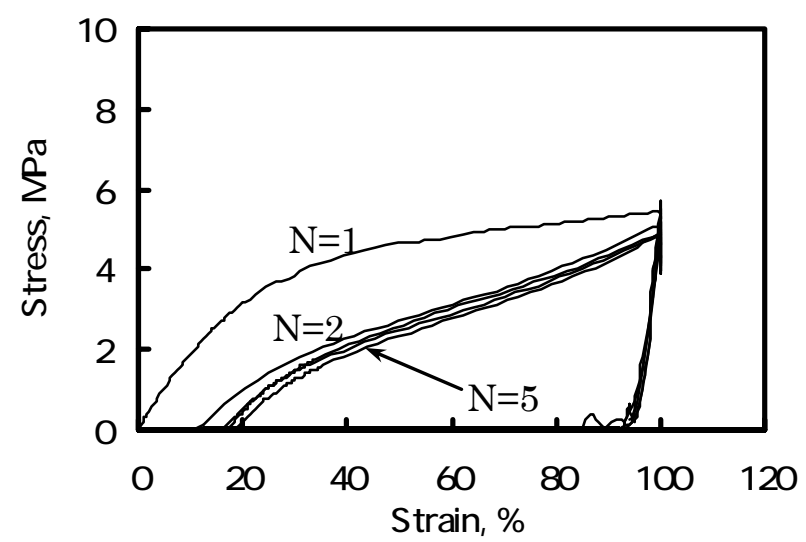

(a) SMP bulk

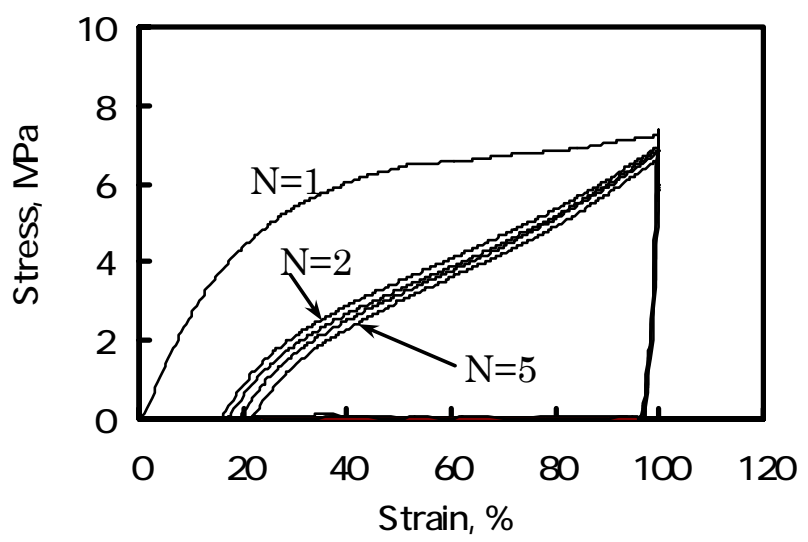

(c) $3.3 \mathrm{wt} \%$

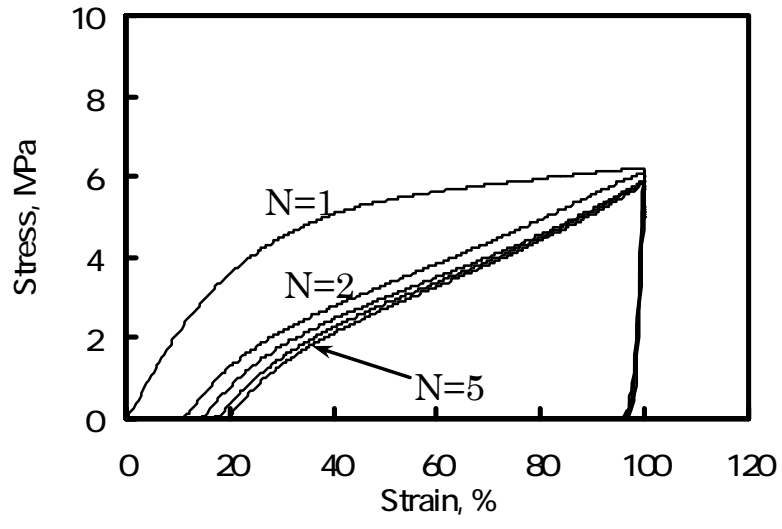

(b) $1.7 \mathrm{wt} \%$

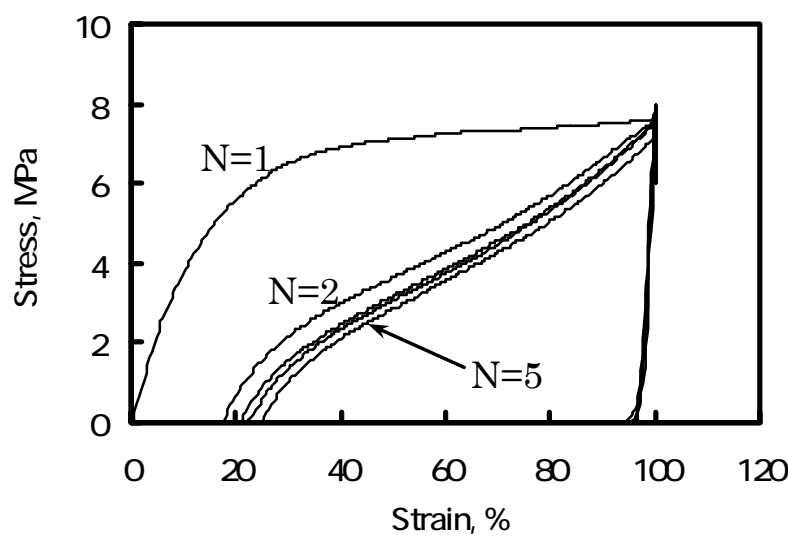

(d) $5.0 \mathrm{wt} \%$

Figure 9. Stress-strain curves in the thermo-mechanical cycle tests at $\varepsilon_{m}=100 \%$ for four materials-(a) SMP bulk, (b) $1.7 \mathrm{wt} \%$, (c) $3.3 \mathrm{wt} \%$ and (d) $5.0 \mathrm{wt} \%$, respectively. 


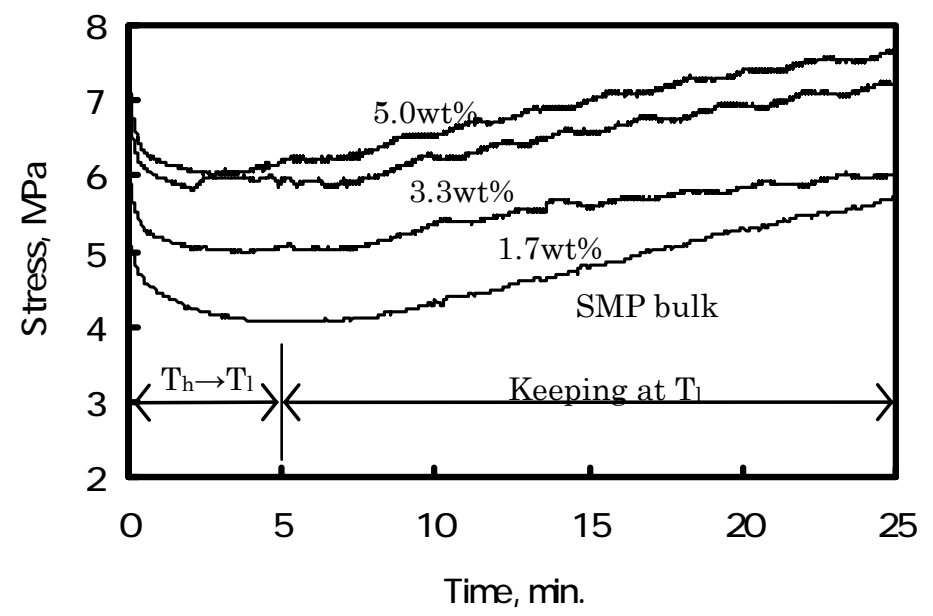

Figure 10. Relationship between stress and time in the process 2 for four materials-SMP bulk, $1.7 \mathrm{wt} \%, 3.3 \mathrm{wt} \%$ and $5.0 \mathrm{wt} \%$.

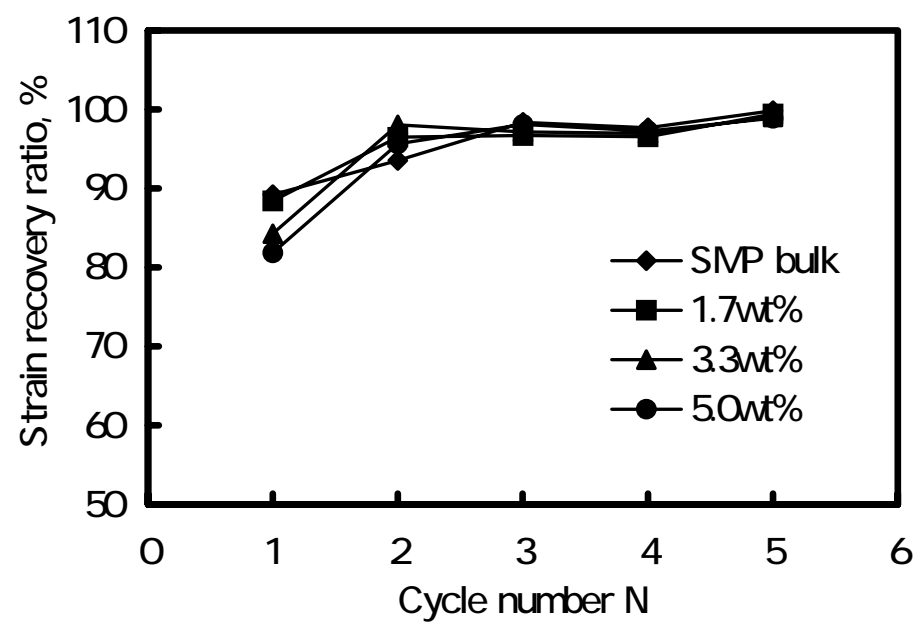

Figure 11. Relationship between strain recovery ratio and cycle number for four materialsSMP bulk, $1.7 \mathrm{wt} \%, 3.3 \mathrm{wt} \%$ and $5.0 \mathrm{wt} \%$. 


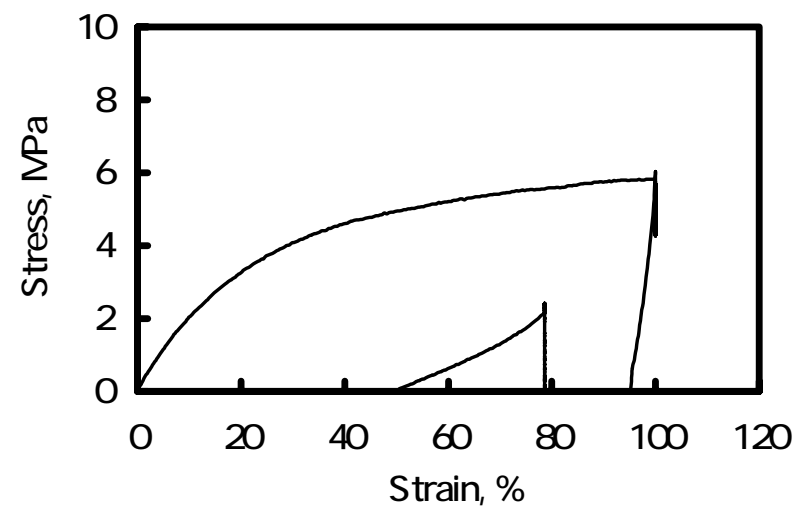

(a) SMP bulk

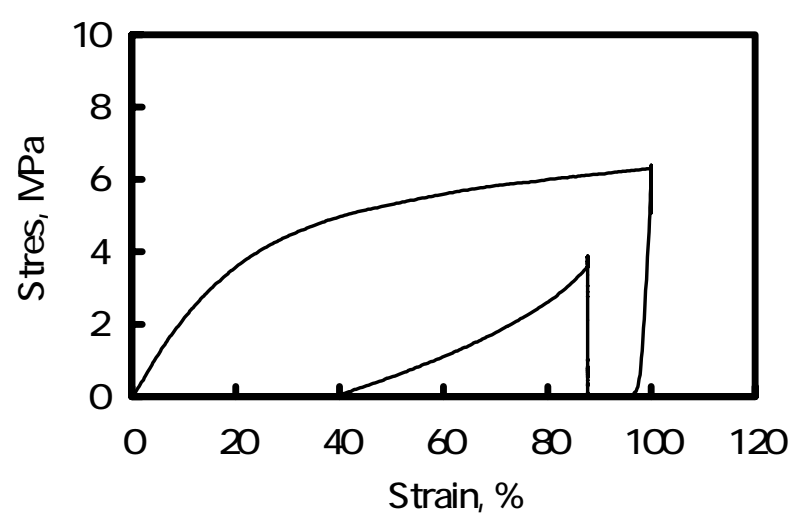

(c) $3.3 \mathrm{wt} \%$

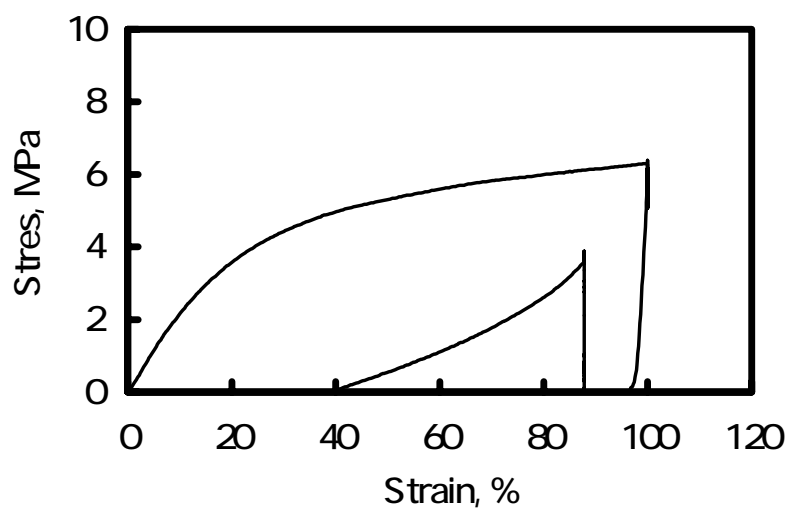

(b) $1.7 \mathrm{wt} \%$

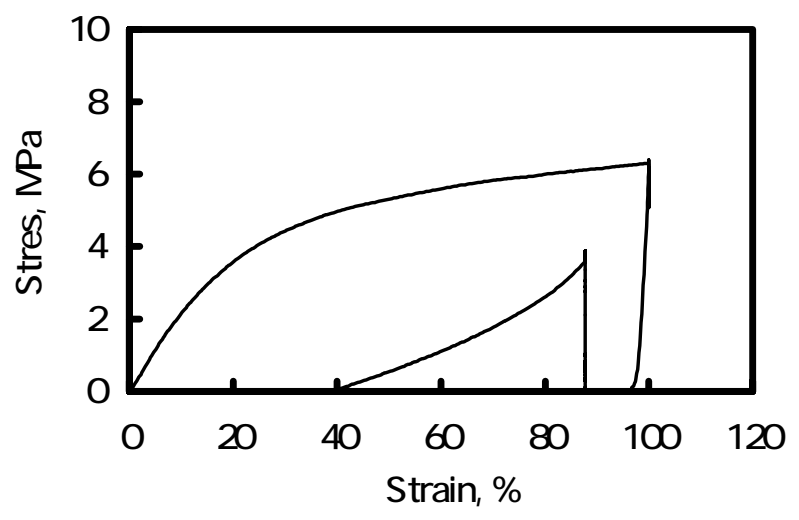

(d) $5.0 \mathrm{wt} \%$

Figure 12. Relationship between stress and strain in the recovery stress cycle test for four materials-(a) SMP bulk, (b) $1.7 \mathrm{wt} \%$, (c) $3.3 \mathrm{wt} \%$ and (d) $5.0 \mathrm{wt} \%$, respectively. 


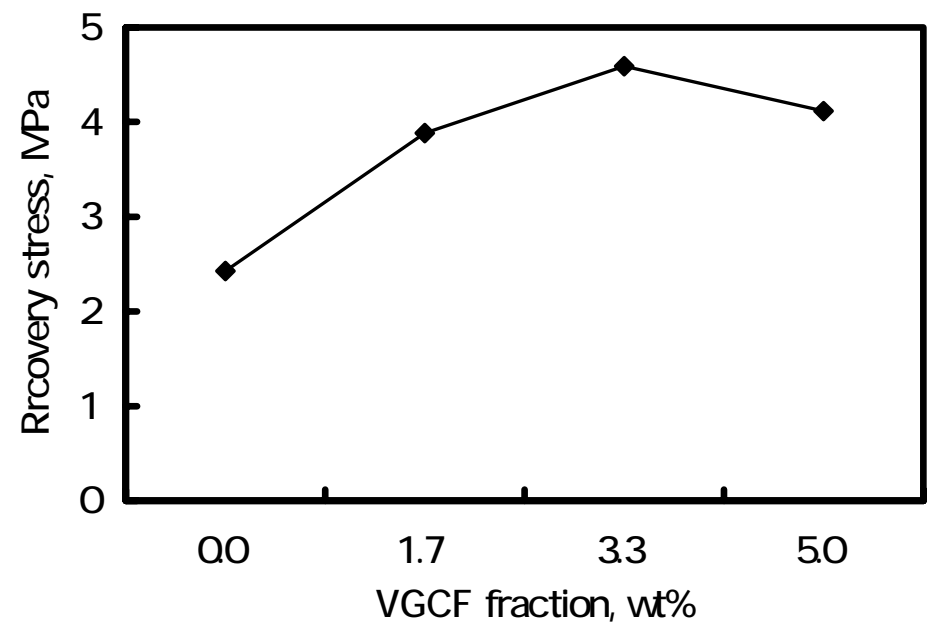

Figure 13. Relationships between recovery stress and VGCF weight fraction for CNT/SMP nanocomposites. 